\title{
The relationship between Organizational Citizenship Behavior (OCB) and Human Resources Empowerment (HRE) Case study: University of Isfahan (Iran)
}

\author{
${ }^{1}$ Nahid Naderi, ${ }^{2}$ Reza Hoveida, \\ ${ }^{1} \mathrm{PhD}$ student of educational administration, Department of Educational and Psychology, \\ University of Isfahan, Isfahan, Iran. (nanaderi84@yahoo.com) \\ ${ }^{2}$ Assistant professor, Department of Educational and Psychology, University of Isfahan, \\ Isfahan, Iran.( r.hoveida@edu.ui.ac.ir)
}

Accepted: June 16, 2013 Published: July 12, 2013

Doi:10.5296/ijhrs.v3i2.3991 URL: http://dx.doi.org/10.5296/ijhrs.v3i2.3991

\begin{abstract}
This research attempts to present an approach for achieving the relationship between organizational citizenship behavior (OCB) and human resource empowerment (HRE) among staff at University of Isfahan. Statistical population of the study was all of the staff in administrative - financial, education-cultural, and research sectors at University of Isfahan. Among them statistical sample was selected randomly. Research method was descriptive correlative and data was collected using two questionnaires: psychological empowerment and organizational citizenship behavior. Mentioned questionnaires had content validity and their reliability was .88 and .86 respectively that were calculated through Choronbach s Alpha. Findings showed that there was a positive and significant relation between total psychological empowerment and organizational citizenship behavior.There was a relation between impact and meaning with organizational citizenship behavior. Also, there showed a significant relation between first pair of focal variables including competence with linear combine all of organizational citizenship behavior variables.
\end{abstract}

Key words: Organizational citizenship behavior, psychological empowerment, Meaning, Impact, Competence.

\section{Introduction}

Research on human resource psychological empowerment began to appear in the literature in the late 1980s. Empowerment defined as a process whereby universities employees and participants develop the competence to take charge of their own growth and resolve their own problems and "Organizational citizenship behavior (OCB) is referred to as a set of discretionary workplace behaviors that exceed one's basic job requirements. They are often described as behaviors that go beyond the call of duty. Research on OCB has been extensive since its introduction nearly twenty years ago" (Zarea, 2012). 
OCBs are still primarily viewed as behaviors that are generally discretionary and less likely to be formally or explicitly rewarded in an organization (Podsakoff et al., 2000).

Human resource Psychological empowerment can possess various roles in organizations. One of the most important of them is creation and enhancement of Organizational citizenship behavior. Designing and clarifying the model of Psychological empowerment and its relation Organizational citizenship behavior between university of Isfahan employees is the main topic of this research.

Thus the researchers intend to help the managers of universities through this research.

\section{Literature Review}

\section{2-1. Human resources psychological empowerment}

Psychological empowerment is defined as "increased intrinsic task motivation manifested in cognitions that reflect an individual's active orientation to his or her work role (Spreitzer, 1995). Since its introduction, the construct of psychological empowerment has been used to measure Human resources psychological empowerment in a number of empirical studies in the context of the service industry (e.g., Chiang \& Jang, 2008; Kim \& George, 2005; Kim et al., 2011; Ro \& Chen, 2011). Specifically, it has been found that psychological empowerment has a positive impact on job satisfaction for American restaurant employees (Gazzoli et al., 2010) and American hospitality workers (Lee et al., 2011), organizational commitment for Korean hotel restaurant employees (Kim et al., 2009), and employee perceived service quality for American service workers (Ping et al., 2010) Organizational Culture, Leadership and Organizational Justice Relationship with Organizational Citizenship Behavior for Higher Learning Institutions in Malaysia(Kadar Khan and Abdul Rashid 2012).Psychological empowerment has three dimensions (Spreitzer 1995):

a. Meaning: Meaning is the value of a work goal or purpose, judged in relation to an individual's own ideals or standards.

b. Competence: Competence(self-efficacy) consisted of an individual's belief human capability to perform activities with skill

c. Self-determination: is an individual's sense of having choice in initiation and regulating actions.

d. Impact: Impact is the degree to which an individual can influence strategic, administrative or operating outcomes at work.

Human resources empowerment is a process by which a empowerment culture is developed. In such culture, goals, decision making borders and the outcome of effects and efforts are shared in the whole project. Human resources empowerment process can be summarized into three stages (Faraji lahijani 2012):

1. Information sharing: it allows human resources to recognize and analyze project situations. Information sharing is initiated with project confidence building and breaking down hierarchical thinking, and it results in increased human resources responsibility. 
2. Autonomy and working independence all across the project boundaries: project boundaries are specified through the goal, values, regulations, target, roles, and project system and structure.

3. Replacing hierarchies with self-managed teams: when a group of human resources is selected with specific responsibilities for working process within project, they plan, execute and manage everything and responsibilities are divided equally. Advantages of self-managed teams include: providing occupational satisfaction, work commitment, better communication between human resources and project managers, more effective decision-making processes, work improvement and development, reduced project costs and project productivity.

\section{2-2. Organizational Citizenship Behavior (OCB):}

OCB is defined as "individual behavior that is discretionary, not directly or explicitly recognized by the formal reward system, and that in the aggregate promotes the effective functioning of the organization" (Organ, 1988, p.4).

Cooperative and discretionary behaviors by employees, called Organizational Citizenship Behaviors (OCB), are regarded as an important individual outcome which promotes effectiveness in organizations (LePine, Erez, \& Johnson, 2002; Kim et al. 2011). OCB refers to various dimensions such as Altruism (e.g., helping specific individuals), Conscientiousness (e.g., going beyond minimally required levels of attendance), Sportsmanship (e.g., tolerating the inevitable inconveniences of work without complaining), Courtesy (e.g., informing others to prevent the occurrence of work-related problems) and Civic Virtue (e.g., participating in and being concerned about the life of the company) (Organ, 1988).

In the educational settings, research on OCB is a recent trend. As psychologists have assumed that to meet the new standards that have been set for schools and universities. The personnel must go out of bounds of minimum performance standards of their duties. At the university level this is desired to increase the overall efficiency of the organization in terms of students' [employees'] satisfaction and performance (Farooqui, 2012).

\section{2-3. Human resources psychological empowerment and OCB}

Bogler and Somech(2004) Study focused on the relationship between teacher empowerment and organizational citizenship behavior (OCB). It examines which empowerment can best predict these outcomes. Pearson correlations and multiple regression analyses indicated that personals perceptions of their level of empowerment are significantly related to their OCBs. Wat and Shaffer (2005) suggest that empowered workers who perceive a high quality social exchange relationship with their manager are likely to engage in OCB. Alge, Ballinger, Tangirala and Oakley (2006) also argue that employees that feel empowered are likely to perceive the link between their actions and broader organizational outcomes and feel more responsibility for helping others over and above what is specified in their job requirements. Harris, Wheeler, \& Kacmar (2009) suggest that employees need to have the workplace freedom to display OCB through empowerment. Also Abazeed (2010) research was about The Effect of Psychological Empowerment on Citizenship Behavior of Employees in Social Security Corporation in Jordan. His findings revealed that there is an impact of 
psychological empowerment on citizenship behavior. The Results also showed that there were no statistical differences among demographic variables of employees regarding the psychological empowerment and citizenship behavior. Kim, Losekoot and Milne (2011) also contend that empowered employees consider their management trustworthy. Kim, Lee and Kang (2011) indicated that the psychological empowerment positively affected on the OCB.

When employee empowerment becomes apparent, (employees become empowered) dimensions of organizational citizenship behavior that presumably and naturally exist in every person find opportunity to emerge and flourish(Nezakati et al. 2012).

\section{The objectives of the study}

Were:

1. Find out the relationship between employees perceptions towards psychological empowerment and OCB.

2. Investigate the relationships that might exist between human resources psychological empowerment items (Meaning, Self-determination, Competence, Impact) and OCB (altruism, conscientiousness, sportsmanship, courtesy, civic virtue).

\section{Hypotheses of the Study}

The researcher proposed three main hypotheses as follows:

1. There is significant relationship between total Human resources employees' psychological empowerment and total OCB.

2. There is significant relationship between total OCB and Human resources psychological empowerment items.

3- There is significant relationship between Human resources psychological empowerment items and OCB items.

\section{Research Methodology}

This is the explanatory research study based on the survey method which measures the relationship between employees' psychological empowerment and organizational citizenship behavior in the University of Isfahan in Iran. Statistical population of the study was all of the staff in administrative $(\mathrm{N}=389)$, financial $(\mathrm{N}=183)$, education-cultural $(\mathrm{N}=189)$, and research sectors $(\mathrm{N}=17)$. Among them statistical sample was selected randomly $(\mathrm{n}=122)$ - financial $(n=56)$, education-cultural $(n=58)$, and research sectors $(n=5)$. Research method was descriptive - correlative and data was collected using two questionnaires: psychological empowerment (Spreitzer, 1995) and organizational citizenship behavior (Podskoff, Mackenzie, Moorman \& Fetter, 1991). Mentioned questionnaires had content validity and their reliability was .88 and .86 respectively that were calculated through Choronbach s Alpha. Chart 1 demonstrates demographic characters in term of Percentage (\%).Insert chart 1 here 


\section{Results:}

a. Descriptive analysis including frequencies, mean and standard deviation are used to study variables (Insert Table 1 here).

b. Correlation analysis is being used to determine total psychological empowerment relates to total $\mathrm{OCB}$ (Insert table 2 here)

According to Table 2 There is significant relationship between total employees' psychological empowerment and total OCB. Therefore first Hypothesis is significant at 0.05 level.

C: Table 3 provides the results of multiple regression analyses which test the hypotheses for the positive impact of psychological empowerment on OCB(Insert table 3 here).

Based on Beta coefficient in table 3, per unit increase in Meaning, the organizational citizenship behavior increases 0.68 unit; per unit increase in Impact, the organizational citizenship behavior increases 0.21 units. Thus hypothesis 3 is significant at 0.05 level in two indicators.

D: Table 4 provides the results of canonical Correlation coefficients between psychological empowerment and organizational citizenship behavior (OCB) dimensions(Insert table 4 here).

Based on the findings of table 4, the correlation between the first pair of central variables is equal to 0.658 . This value shows the existence of a medium linear correlation between psychological empowerment indicators and any linear combination of organizational citizenship behavior (OCB) variables. There is a correlation between the first pair of organizational citizenship behavior (OCB) indicators and competence.

The first value of Chi-square equals to 750581, corresponding to Wilks coefficient at $\mathrm{P} \leq$ 0.05 level is significant indicating that all correlations in the first pair of canonical variables are not equal to zero.

The second value, equal to 90789 at $\mathrm{P} \leq 0.05$ level is not significant. Such for the third and fourth value, all of the correlations are equal to zero.

Thus, the third hypothesis has solely been confirmed in the first pair of central variables. By calculating canonical correlation coefficient in table 4, the ratio of pair correlations between indicators are specified.

\section{Discussion and conclusions:}

The main aim of this survey was to investigate relationship between organizational citizenship behavior (OCB) and human resource empowerment (HRE) among staff at University of Isfahan in Iran. Considering the results of table 2,

There is a relationship between Human resources psychological empowerment and 
organizational citizenship behavior (OCB).In other hand human resources empowerment can bring positive OCB. This conclusion is compatible with the findings of Bogler and Somech (2004), Yun, Cox, J., Jr. and Salam,(2007), Abazeed (2010), Zhang, Lam, and Chen (2011), Kim, Lee and Kang(2011)and Nezakati et al. (2012).Therefore, hypothesis 1 is supported. According to table 3, there is a direct and significant relationship between two indicators and staff's Organizational citizenship behavior (OCB). Based on the results of table 3, the predictors of organizational citizenship behavior are meaning and impact. Therefore, hypothesis 2 is supported in meaning $(\mathrm{R} 2=0.328)$ and impact $\left(\mathrm{R}^{2}=0.364\right)$. These results are compatible with the survey results Bogler and Somech (2004).

In table 4, there is a correlation between first pair of OCB indicators and competence. In this table first Chi-square, equal to 750581, corresponding to Wilks coefficient at P 0.05 level denotes this correlation as significant. So hypothesis 3 is supported solely in the first pair of canonical variables. Empowering frontline employees is a desirable managerial practice particularly in the higher education where frontline employees directly interact with faculties and students to deliver services. 0n the other hand who display a high OCB in terms of Empowerment to provide a better experience for clients may actually be sacrificing the opportunity to improve their own average check. Thus management should probably review their recruitment and training processes - if staff psychological empowerment is vital to doing services.

Without empowerment, universities managers cannot be successful in doing mission of higher education. The managers are the most important factor in human resources empowerment because they influence directly and indirectly on all organization factors. That managers should provide necessary context for empowerment by delegating more power to employees, giving them independence and freedom, providing a collaborative atmosphere, feeling meaning and impact at work, and eliminating conditions which lead to powerlessness of employees, since empowerment of human resources offers potential capacities for utilizing human resources abilities which are not used totally, and in fact, it creates a powerful organizational citizenship behavior between employees. Higher human resources empowerment leads organization closer to achieving OCB between staff of the university.

\section{Limitations and Future Research:}

It should be noted that the current research has several limitations which provide opportunities for further research. First, the sample size for this study was relatively small (n = 122). Also, the generalizability of the findings is limited given that only a convenience sample of employees at university of Isfahan was used to test research hypotheses. Future research, therefore, could perhaps attempt to replicate and enlarge upon the present findings by using a larger sample size from different universities in higher education system, such as other public, Azad, Non-profit and Payame Noor universities. Second, this study only examined the direct impact of psychological empowerment on OCB due to the small sample size. However, it would have been more robust if other variables related to both psychological empowerment and the OCB variables had been included to detect any confounding effect on the relationships of interest. Lastly, it would be useful for future 
research to scrutinize the present findings with a qualitative approach (e.g., in-depth interviews) to determine faculties and students and staff perception of the possible causes of the relationships identified in this study.

\section{References:}

Abazeed, Riad(2010). The Effect of Psychological Empowerment on Citizenship Behavior of Employees in Social Security Corporation in Jordan, An- Njah University Journal for Research-Humanities.24(2),P:39-56

Alge, B. J., Ballinger, G. A., Tangirala, S., \& Oakley, J. L. (2006). Information privacy in organizations: Empowering creative and extrarole performance. Journal of Applied Psychology, 91(1), 221.

Bogler, R., and Somech, A.(2004). Influence of teacher empowerment on teacher's organizational commitment professional commitment and organizational citizenship behavior in schools. (www. Elsevier, com/locate/tate).

Chiang, C. F., \& Jang, S. C. S. (2008). The Antecedents and Consequences of Psychological Empowerment: The Case of Taiwan's Hotel Companies. Journal of Hospitality \& Tourism Research, 32(1), 40.

Faraji, lahijani, P, Nojedehi.P, Haghanipour,A(2012). Human Resources Empowerment Strategies in Development Projects, Engineering Research and Applications (IJERA), Vol. 2, Issue 3, May-Jun 2012, pp.2760-2761(ISSN: 2248-9622 www.ijera.com).

Harris, K. J., Wheeler, A. R., \& Kacmar, K. M. (2009). Leader-member exchange and empowerment: Direct and interactive effects on job satisfaction, turnover intentions, and performance. The Leadership Quarterly, 20(3), 371-382.

Farooqui,M,R,(2012). Measuring Organizational Citizenship Behavior (OCB) as a Consequence of Organizational Climate (OC), Asian Journal of Business Management 4(3): 294-302.

Gazzoli, G., Hancer, M., \& Park, Y. (2010). The Role and Effect of Job Satisfaction and Empowerment On Customers ${ }^{\text {ee }}$ Perception of Service Quality: a Study in the Restaurant Industry. Journal of Hospitality \& Tourism Research, 34(1), 56.

Kadar Khan,S, Abdul Rashid,M,Z(2012). The Mediating Effect of Organizational Commitment in the Organizational Culture, Leadership and Organizational Justice Relationship with Organizational Citizenship Behavior: A Study of Academicians in Private Higher Learning Institutions in Malaysia. International Journal of Business and Social Science, Vol. 3 No. 8,PP:83-91.

Kim, B. P., \& George, R. T. (2005). The relationship between leader-member exchange (LMX) and psychological empowerment: A quick casual restaurant employee correlation study. Journal of Hospitality \& Tourism Research, 29(4), 468.

Kim,B,C(P), Losekoot,E, and Milne,S(2011). Impact of Psychological Empowerment for Individual Service Workers, the $2392^{\text {nd }}$ International Research Symposiums in Service Management, Yogyakarta, INDONESIA, PP: 392-401.

Kim,So-H,Lee.W-J,Kang,J-H,(2011). Transformational Leadership, Empowerment, and OCB in Team Sport Organizations: Mediating Effect of Empowerment, North American Society for Sport Management Conference (NASSM 2011). 


\section{MInstitute Macrink $_{\text {inth }}$}

Lee, G., Kim, B. C. P., Perdue, R., \& Magnini, V. (2011). Time-Verying Effects of Empowerment on Job Satisfaction for Customer-Contact versus Non-Customer-Contact Employee Groups.

LePine, J. A., Erez, A., \& Johnson, D. E. (2002). The nature and dimensionality of organizational citizenship behavior: A critical review and meta-analysis. Journal of Applied Psychology, $87(1), 52$.

Nezakati, H, Kohzadi,V, Karimi, F(2011). Fostering Organizational Citizenship Behavior (OCB) Through Human Resources Empowerment (HRE): www.wbiconpro.com/27.Nezakati.pdf).

Organ, D. W. (1988). Organizational citizenship behavior: The good soldier syndrome: Lexington Books/DC Heath and Com.

Podskoff, P. M., Mackenzie, S., Moorman , R. \& Fetter , R. (1990). Transformational leader behaviors and their effects on organizational behaviors. The leadership Quarterly, 1, 107142.

Podsakoff, P. M., MacKenzie, S. B., Paine, J. B., \& Bachrach, D. G. (2000). Organizational citizenship behaviors: A critical review of the theoretical and empirical literature and suggestions for future research. Journal of Management, 26(3), 513.

Ro, H., \& Chen, P.-J. (2011). Empowerment in hospitality organizations: Customer orientation and organizational support. International Journal of Hospitality Management, 30(2), 422428. doi: DOI: 10.1016/j.ijhm.2010.09.003

Spreitzer, G., M. (1995). Psychological empowerment in the workplace dimensions, measurement and validation. The academy of management Journal.38(5), PP1442 1465.

Wat, D., \& Shaffer, M. A. (2005. Equity and relationship quality influences on organizational citizenship behaviors: The mediating role of trust in the supervisor and empowerment. Personnel Review, 34(4), 406-422.

Zhang,J,A,Lam,w. and Chen,Z,(2011).Relationship between leader - members exchange and organizational citizenship behavior: Examining the moderating role of empowerment. Asia Pacific Journal Management, 28(3).P:609-626.

Zarea,H(2012). Organizational Citizenship Behaviors and Their Relationship to Social Capital in Public Organizations of Qom Province, Iranian Journal of Management Studies (IJMS) Vol.5, No.1, PP: 79-96.

Yun, S., Cox, J., Jr. H., P.and Salam, S. (2007). The effects of leadership and job satisfaction on team citizenship. International journal of Leadership studies 2(3), P: 103-124. 


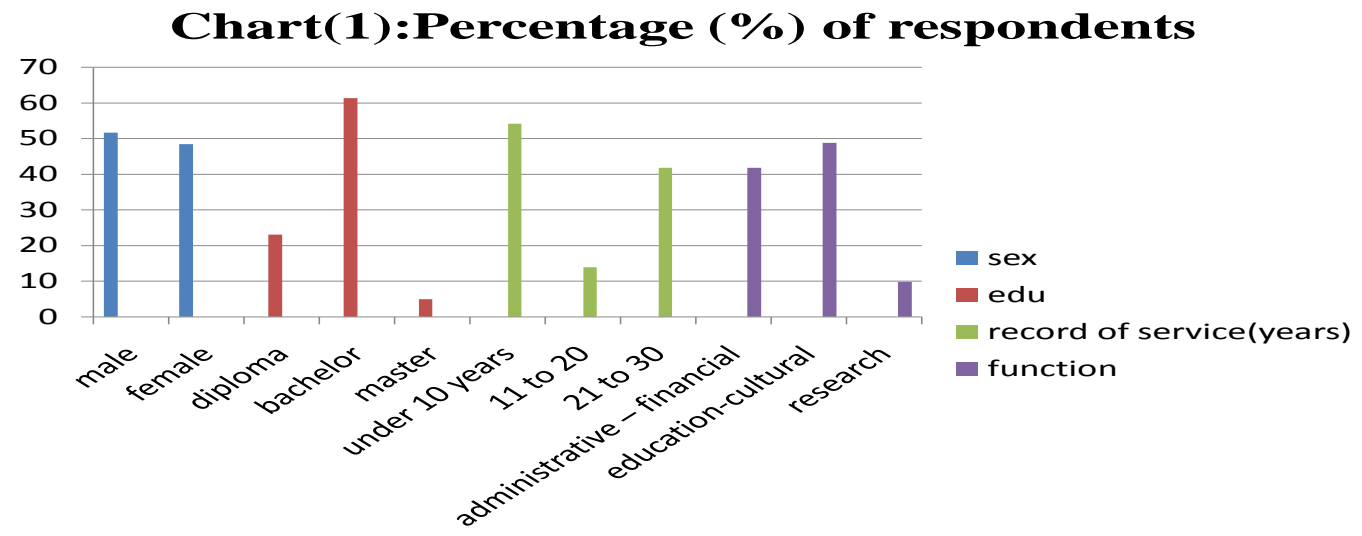

Table 1: Descriptive statistics

\begin{tabular}{|c|c|c|c|}
\hline variables & Items & $\bar{X}$ & $S D$ \\
\hline \multirow{3}{*}{$\begin{array}{c}\text { psychological } \\
\text { empowerment }\end{array}$} & Competence & $09 / 17$ & $3 / 32$ \\
\cline { 2 - 4 } & Self-determination & $04 / 14$ & $4 / 27$ \\
\cline { 2 - 4 } & Impact & $13 / 20$ & $4 / 34$ \\
\hline \multirow{3}{*}{$\begin{array}{c}\text { organizational } \\
\text { citizenship behavior }\end{array}$} & Meaning & $16 / 57$ & $4 / 56$ \\
\cline { 2 - 4 } & conscientiousness & $17 / 74$ & $2 / 80$ \\
\cline { 2 - 4 } & courtesy & $9 / 37$ & $2 / 15$ \\
\cline { 2 - 4 } & altruism & $13 / 52$ & $2 / 83$ \\
\cline { 2 - 4 } & cportsmanship & $5 / 87$ & $2 / 22$ \\
\cline { 2 - 4 } & & $17 / 77$ & $4 / 22$ \\
\hline
\end{tabular}

Results from SPSS output

Table 2: Correlation

\begin{tabular}{|c|c|}
\hline variables & Total OCB \\
\hline Total psychological empowerment & $\begin{array}{c}0.390=r \\
=0 / 000 p \\
n=122\end{array}$ \\
\hline
\end{tabular}


Table 3: Multiple (step by step) regressions between psychological empowerment and OCB indicators

\begin{tabular}{|c|c|c|c|c|c|c|c|c|c|c|}
\hline \multicolumn{2}{|c|}{ Criterion } & Predictor & $\mathbf{R}$ & $\mathbf{R 2}$ & $\mathbf{F}$ & $\mathbf{P}$ & B & Beta & $\mathbf{t}$ & sig \\
\hline \multirow[t]{2}{*}{$\mathrm{OCB}$} & $\begin{array}{l}\text { First } \\
\text { Step }\end{array}$ & Meaning & 0.573 & 0.328 & $58 / 85$ & 0.001 & 1.38 & 0.57 & $7 / 68$ & 0.001 \\
\hline & $\begin{array}{c}\text { Second } \\
\text { Step }\end{array}$ & $\begin{array}{l}\text { Meaning } \\
\text { Impact }\end{array}$ & 0.603 & 0.364 & 33.99 & 0.001 & $\begin{array}{l}1.65 \\
0.55\end{array}$ & $\begin{array}{l}0.68 \\
0.21\end{array}$ & $\begin{array}{l}8.05 \\
2.58\end{array}$ & $\begin{array}{l}0.001 \\
0.011\end{array}$ \\
\hline
\end{tabular}

Table 4: canonical Correlation coefficients between psychological empowerment and organizational citizenship behavior (OCB) dimensions

\begin{tabular}{|c|c|c|c|c|c|}
\hline factors & $\begin{array}{c}\text { canonical } \\
\text { Correlation } \\
\text { coefficients }\end{array}$ & Wilks & Chi-square & $\begin{array}{c}\text { Degree of } \\
\text { Freedom }\end{array}$ & $\begin{array}{c}\text { Significant } \\
\text { level }\end{array}$ \\
\hline 1 & 0.658 & 0.521 & 750581 & 20 & $0 / 000$ \\
\hline 2 & 0.180 & $0 / 919$ & 90789 & 12 & 0.635 \\
\hline 3 & 0.162 & 0.950 & 50957 & 6 & 0.428 \\
\hline 4 & 0.156 & 0.976 & 20855 & 2 & 0.240 \\
\hline
\end{tabular}

